This is the last draft sent to the Editorial by the authors of the article:

M. GÓMEZ, L. RANCEL, B. J. FERNÁNDEZ, S.F. MEDINA

"Evolution of austenite static recrystallization and grain size during hot rolling of a $\mathrm{V}$ microalloyed steel"

Materials Science and Engineering A

Vol. 501 (2009), Pages: 188-196

DOI: 10.1016/j.msea.2008.09.074

ISSN: 0921-5093

To be published in Digital.CSIC, the Institutional Repository of the Spanish National Research Council (CSIC)

See more papers from the authors on:

$\underline{\text { http://digital.csic.es }}$

http://www.researcherid.com/rid/B-7922-2008 


\title{
Evolution of austenite static recrystallization and grain size during hot rolling of a V-microalloyed steel
}

\author{
Manuel Gómez, Lucía Rancel, Bernardo J. Fernández, Sebastián F. Medina
}

National Center for Metallurgical Research, (CENIM-CSIC), Av. Gregorio del Amo 8, 28040 Madrid, Spain.

mgomez@cenim.csic.es, smedina@cenim.csic.es

\begin{abstract}
Laboratory double-deformation isothermal tests and multipass continuous-cooling hot torsion tests were used to study the static recrystallization of austenite under isothermal and anisothermal conditions as well as to simulate the hot rolling of a $0.13 \% \mathrm{~V}$ microalloyed steel. Characterization of the evolution of austenite microstructure was carried out. It has been verified that no-recrystallization temperature $\left(T_{\mathrm{nr}}\right)$ approximately corresponds to the temperature where recrystallization starts to be incomplete during rolling. However, incomplete recrystallization is visually evident at temperatures $25-50{ }^{\circ} \mathrm{C}$ below $T_{\mathrm{nr}}$, where grain elongation and increase in aspect ratio with temperature drop start to be significant. An accurate method to estimate the recrystallized fraction during hot rolling from stress-strain data and with no need of metallographic studies has been designed. The results of this method have been compared to metallographic measurements, the values of anisothermal fractional
\end{abstract}


softening and the accumulated stress measured in the MFS plots at $\mathrm{T}<T_{\mathrm{nr}}$. A pronounced austenite grain refinement has been detected in the first hot rolling passes after reheating, as grain size decreases from $155 \mu \mathrm{m}$ to $27 \mu \mathrm{m}$ in six passes. If the effect of grain size on recrystallization and precipitation is taken into account, the correlation of isothermal and continuous cooling tests as well as the relationship between SRCT and $T_{\mathrm{nr}}$ or RLT temperatures can be better understood.

\section{Keywords}

Microalloyed steels; Hot rolling; Static recrystallization; Austenite grain size; Anisothermal Softening.

\section{Introduction}

The static recrystallization of microalloyed steels after hot deformation can be obstructed by the pinning effect exerted by strain induced precipitates. In the curves that represent the recrystallized fraction against post-deformation isothermal holding time $\left(\left(X_{\mathrm{a}}(\mathrm{t})\right)\right.$, the inhibition of recrystallization by precipitates is manifested by the formation of plateaus that temporarily interrupt the typical sigmoidal shape of an Avrami's law [13]:

$X_{a}=1-\exp \left(-\ln 2\left(\frac{t}{t_{0.5}}\right)^{n}\right)$ 
The exponent $n$ usually takes values between 1 and $2[1,4,5]$ and according to some authors it depends on temperature [6-8]. $t_{0.5}$ is the time corresponding to a recrystallized volume fraction of $50 \%$, which depends on temperature $T$, equivalent pass strain $(\varepsilon)$, strain rate $(\dot{\varepsilon})$, austenite grain size $D$ and chemical composition of steel according to [9]:

$t_{0.5}=A \varepsilon^{p} \mathcal{E}^{q} D^{s} \exp \left(\frac{Q}{R T}\right)$

where $Q$ is the apparent activation energy, $R$ is the universal gas constant ( $8.3145 \mathrm{Jmol}^{-}$ ${ }^{1} \mathrm{~K}^{-1}$ ) and $p, q, s$ and $A$ are constants.

The temperature limit between the stages of full recrystallization and beginning of recrystallization inhibition as a consequence of precipitation comes at a point known as Static Recrystallization Critical Temperature (SRCT) $[9,10]$. On the other hand, in a continuous-cooling multipass thermomechanical test, the temperature below which the recrystallization of austenite during the interpass time between successive passes starts to be incomplete is known as temperature of no-recrystallization $\left(T_{\mathrm{nr}}\right)$ [2].

The microstructure of austenite just before cooling to room temperature has a major influence on final ferrite microstructure [11,12]. Therefore, one of the most important aspects to be studied is the accurate assessment of the strengthening state of austenite and the quantification of the volume fraction of recrystallization during rolling at temperatures below $T_{\mathrm{nr}}$ and especially at the end of rolling, near $A_{\mathrm{r} 3}$. To carry out this 
characterization, metallographic studies can be used [13,14], but metallography is a time-consuming and not always successful technique. Several mathematical models have been developed for the study of recrystallization or softening kinetics during hot rolling of steels, i.e. under non-isothermal conditions $[15,16]$. The "anisothermal fractional softening” method $[17,18]$ gives an approximation of the recrystallized fraction, but this technique includes the contribution of recovery to softening, which can be very high under certain deformation conditions and/or material characteristics [19]. Besides, it is sometimes necessary to know other empirical constitutive parameters or to make preliminary tests to approximate the yield stress of a fully recrystallized material $[18,20]$.

Niobium is known to be the microalloying element that most delays static recrystallization kinetics, even when it is in solution in the austenite $[1,21]$. The influence of vanadium (dissolved or precipitated) on static recrystallization is weaker but still significant, as can be seen in the increase in the values of $t_{0.5}$, activation energy and SRCT for higher V additions [7,22-24]. A strong solute drag effect of V on the kinetics of metadynamic recrystallization has also been described [24]. In this work the evolution of static recrystallization of austenite is characterized in a vanadium microalloyed steel. Thermomechanical tests are carried out under isothermal and continuous cooling conditions and conclusions about the relationship between the results coming from both thermal paths are extracted. An empirical method to estimate the recrystallized fraction during rolling from the stress-strain data obtained in the thermomechanical tests is presented and comparison with the results of metallography and the technique of anisothermal fractional softening is done. 


\section{Experimental Procedure}

The steel studied was manufactured by Electroslag Remelting (ESR) in a laboratory unit capable of producing $30 \mathrm{~kg}$ ingots. This technique avoids macrosegregation, both in alloying elements and impurities, and there is considerably less microsegregation. These effects are often present in conventional ingots and continuous casting billets. As Table 1 shows, the steel has $0.48 \%$ carbon content and $0.13 \%$ vanadium and contains a residual Ti content.

Double-deformation isothermal tests as well as multipass hot rolling simulation tests were carried out in a computer-controlled hot torsion machine, on specimens with a gauge length of $50 \mathrm{~mm}$ and a diameter of $6 \mathrm{~mm}$. Prior to the torsion tests the specimens were austenitized during $10 \mathrm{~min}$ at $1200{ }^{\circ} \mathrm{C}$, a temperature high enough to completely dissolve the V precipitates [25]. However, it should be taken into account that, despite the very low Ti content, a certain amount of undissolved TiN can remain after reheating, as this type of precipitate is very stable [26]. The calculated temperature for its complete solution in austenite is $1368{ }^{\circ} \mathrm{C}$. The calculated solubility temperatures and the reheating conditions are shown in Table 2.

After reheating, the temperature was rapidly lowered to that corresponding to the first deformation pass in each test. In the isothermal double-deformation experiments, this temperature was maintained after deformation during a certain holding time, after which a longer second deformation was applied in order to calculate recrystallized fraction $\left(X_{a}\right)$. The value of $X_{a}$ was measured using the "back extrapolation” technique [27]. This 
method presents the advantage of determining the recrystallized fraction instead of the softened fraction, i.e. the effect of recovery is excluded from the double deformation data [13], so more accurate comparison with observed microstructures can be carried out.

Temperatures of $950{ }^{\circ} \mathrm{C}, 1000{ }^{\circ} \mathrm{C}, 1050{ }^{\circ} \mathrm{C}$ and $1100{ }^{\circ} \mathrm{C}$ and several holding times between $1 \mathrm{~s}$ and $500 \mathrm{~s}$ were used in order to build the curves of recrystallized volume fraction against time $\left(X_{\mathrm{a}}(\mathrm{t})\right)$ as well as the Recrystallization-Precipitation-TimeTemperature (RPTT) diagram [7,28-30], where the interaction between these two processes is clearly observed. The equivalent strain $(\varepsilon)$ applied in the first pass was 0.20 , lower than the critical strain which leads to the start of dynamic recrystallization. The strain rate $(\dot{\varepsilon})$ was kept at $3.63 \mathrm{~s}^{-1}$.

In some samples the second deformation after holding time was replaced by a waterquench and subsequent metallographic preparation. Microstructure was observed in optical microscope to verify the accuracy of back extrapolation method in determining the recrystallized fraction and to compare with the results of multipass simulations. All the microstructural studies carried out in this study were done observing more than 20 fields on a longitudinal surface of the specimens at $2.65 \mathrm{~mm}$ from the axis. To reveal the prior austenite grain boundaries, the samples were etched with an aqueous solution of saturated picric acid mixed with a wetting agent. Some droplets of hydrochloric acid were added just before etching to activate the solution.

In the hot rolling simulation tests, the temperature of the first pass was $1150{ }^{\circ} \mathrm{C}$. The simulations consisted of 20 passes made under continuous cooling conditions, with a 
temperature step of $25^{\circ} \mathrm{C}$ between passes, the last pass being carried out at $675^{\circ} \mathrm{C}$. The time between successive deformations, known as “interpass time” ( $\Delta \mathrm{t})$ was equal to 20

s. The strain and strain rate applied in each pass were the same as those used in isothermal tests $\left(\varepsilon=0.20, \dot{\varepsilon}=3.63 \mathrm{~s}^{-1}\right)$. After determining the critical hot rolling temperatures ( $\left.T_{\mathrm{nr}}, A_{\mathrm{r} 3}\right)$, supplementary quench-interrupted tests were carried out in order to evaluate the evolution of microstructure (grain size, recrystallization) during rolling. In these tests, samples were deformed following the same schedule until they were water-quenched from certain temperatures along rolling schedule. In most cases the sample suffered a last deformation step and then the temperature was lowered $25^{\circ} \mathrm{C}$ during the corresponding $\Delta \mathrm{t}$ to reach the quenching temperature, so microstructure just before the application of the rolling pass was assessed. In some case, the sample was quenched immediately after deformation to observe the microstructure prior to a hypothetical cooling from a certain last hot rolling-pass temperature. The austenite grain size $(D \gamma)$ and aspect ratio were determined by means of the linear intersection technique. Recrystallized fraction was measured using standard point-counting metallographic technique. Distinction of recrystallized and deformed grains was based on the shape and size of the grains as well as the appearance of grain boundaries $[19,31]$.

\section{Results}

\subsection{Double deformation isothermal tests and multipass hot rolling simulations}

First of all, the initial austenite grain size after reheating was determined. As shown in

Table 2, the steel studied had a grain size of $155 \mu \mathrm{m}$ after $10 \mathrm{~min}$ at $1200{ }^{\circ} \mathrm{C}$. The 
torsion test gives the values of torque applied versus the number of turns made on the specimen, which are transformed respectively into equivalent stress and strain using Von Mises criterion [32]. Figure 1a shows the relationship between recrystallized fraction $\left(X_{a}\right)$ and time. At high temperatures $\left(1100^{\circ} \mathrm{C}\right)$ the recrystallization progresses continuously following an Avrami's law until completion. However, at a lower temperature $\left(1050{ }^{\circ} \mathrm{C}\right)$ a plateau is formed, indicating a period of time where the recrystallization is inhibited by the pinning forces exerted by precipitates. After the plateau, the recrystallization progresses again until it is complete, following a similar trend to that recorded before the plateau. At the lowest temperatures $\left(1000^{\circ} \mathrm{C}, 950{ }^{\circ} \mathrm{C}\right) \mathrm{a}$ double plateau can be observed. Previous studies have verified by means of differential thermal analysis (DTA) [3] and lattice parameter comparison [22,33] that this phenomenon results from the formation of two different types of precipitates having different stoichiometries and similar solubility temperatures. In the particular case of VTi steels, the precipitate is initially a $\mathrm{N}$ rich $(\mathrm{Ti}, \mathrm{V})$ carbonitride that produces the first plateau of the curves. Stoichiometry changes with holding time after deformation to a C-richer carbonitride with higher V content, which would cause the second plateau [22].

Curves of Fig. 1a have been used to deduce the temperatures and times corresponding to different recrystallized fractions, as well as the induced precipitation start $\left(P_{\mathrm{s}}\right)$ and finish $\left(P_{\mathrm{f}}\right)$ times, given by the times of the beginning and the end of the plateaus of inhibition of recrystallization [3]. In this way, the RPTT diagram of Figure $\mathbf{1 b}$ has been drawn. The horizontal asymptote of the $P_{\mathrm{s}}$ and $P_{\mathrm{f}}$ curves is the Static Recrystallization Critical Temperature (SRCT) $[9,10]$. As there are two plateaus, two $P_{\mathrm{s}}$ and $P_{\mathrm{f}}$ curves and two values of SRCT corresponding to two separated stages of precipitation can be distinguished. 
Figure 2a shows the stress-strain curves of the 20 hot rolling passes simulated. At first deformations, stress raises as temperature decreases, after which there is a change in the slope with a growth in the stress that means a greater tendency to strengthening. The meaning of this figure is better explained by observing Figure 2b, which shows the graphic representation of mean flow stress (MFS) versus the inverse of the absolute temperature. MFS is determined in each step by dividing the area below the stress-strain curve by the strain applied. In Fig. $\mathbf{2 b}$ it is possible to distinguish three different zones corresponding to complete recrystallization between passes at high temperatures (I), accumulation of strengthening due to partial inhibition of recrystallization (II) and transformation of austenite to ferrite and pearlite (III) [2]. The intersection of the straight regression lines of phases I and II defines the value of $T_{\mathrm{nr}}$ and the intersection of the regression lines of phases II and III determines the value of $A_{\mathrm{r} 3}$ [2]. The magnitude known as "accumulated stress" $(\Delta \sigma)[34]$ will be given by the length of the vertical segment drawn between the regression lines of phases I and II, as illustrated in Fig. $\mathbf{2 b .}$ The value of $\Delta \sigma$ informs about the progressive strengthening of austenite during rolling at temperatures below $T_{\mathrm{nr}}$. Figure 3 shows the evolution of accumulated stress during hot rolling. $\Delta \sigma$ is zero at $\mathrm{T}=T_{\mathrm{nr}}$ and grows during phase II to reach its maximum value at $A_{\mathrm{r} 3}$ [34].

\subsection{Microstructural evolution of austenite during hot rolling}

Figure 4 shows the microstructural evolution of austenite during a wide range of deformation temperatures along the rolling schedule represented in Fig. 2. Starting from an initial grain size of $155 \mu \mathrm{m}$ (Fig. 4a), grain is significantly refined by successive 
recrystallizations in the first rolling passes above $T_{\mathrm{nr}}$. For example, the grain is refined to $53 \mu \mathrm{m}$ after two passes and it reaches $27 \mu \mathrm{m}$ before applying deformation at $1000{ }^{\circ} \mathrm{C}$, i.e. the value of mean grain size is divided by six in six passes. Elongation of grains that do not recrystallize during interpass time is observed at lower temperatures. Although $T_{\mathrm{nr}}$ is equal to $897^{\circ} \mathrm{C}$, grain elongation starts to be remarkable at temperatures near 850 ${ }^{\circ} \mathrm{C}$. In the pictures corresponding to the lowest temperatures the progressive strengthening of the austenite can be easily seen. For example, it can be observed how the grains elongate as a result of a deformation of $\varepsilon=0.20$ at 800 (Figs. 4d-4e). On the other hand, the interpass time of $20 \mathrm{~s}$ is very short to permit a high degree of recrystallization at those low temperatures, so austenite accumulates a progressive strengthening and approaches to the typical "pancake” microstructure. This can be verified observing the weak effect of interpass time from $775{ }^{\circ} \mathrm{C}$ to $750{ }^{\circ} \mathrm{C}$ (Figs. $\mathbf{4 f - 4 g}$ ).

The curve of Figure 5 has been obtained from the analysis of Fig. 4. In this figure, the evolution of average austenite grain size and aspect ratio during rolling is graphically represented against quenching temperature. The last deformation temperature of each sample was $25^{\circ} \mathrm{C}$ higher than quenching temperature. It can be seen that austenite grain refinement occurs mainly in the first rolling passes, before reaching no-recrystallization temperature, as a result of successive recrystallizations from a relatively coarse initial grain size of $155 \mu \mathrm{m}$. This is in agreement with several equations proposed for austenite recrystallized grain size and interpass grain growth for CMn and microalloyed steels $[1,4,5,31]$. Fig. 5 shows that the experimental values of grain size would converge at temperatures near $T_{\mathrm{nr}}$ with the line corresponding to recrystallized grain size proposed by Sellars [1] (assuming that prior grain size $d_{0}$ is equal to recrystallized grain size from previous pass $d_{\text {rex }}$, i.e. grain growth is not considered). The austenite grain size at $T=$ 
$T_{\mathrm{nr}}$ is close to $20 \mu \mathrm{m}$, which does not greatly differ from the values found by other authors [8] for Ti steels with two different Ti contents and initial grain sizes and similar deformation conditions. The substantial grain refinement occurred in the first rolling passes makes the grain size at $\mathrm{T}=T_{\mathrm{nr}}$ to be practically independent on the initial microstructure after reheating $[8,35]$. However, the grain size depends on pass strain and finer final austenite grain sizes close to $10 \mu \mathrm{m}$ would be desired for high strength steels. Below $T_{\mathrm{nr}}$, and especially in the last passes, interpass time is not long enough for the complete recrystallization of all austenite grains. Pinning forces exerted by precipitates take comparable or even higher values than the driving forces for recrystallization $[28,36,37]$ and some grains elongate progressively. This can be verified by evaluating the austenite grain aspect ratio [36], which represents the ratio between the number of grains detected per unit length in deformation direction and its perpendicular. In this case, the directions perpendicular and parallel to the axis of torsion sample have been respectively taken. Fig. 5 shows that the growth of aspect ratio with the temperature drop is remarkably faster when the last pass is carried about $50{ }^{\circ} \mathrm{C}$ below $T_{\mathrm{nr}}$. The average value of aspect ratio at $\mathrm{T}=T_{\mathrm{nr}}$ is about 1.1.

\subsection{Approximation of recrystallized fraction during hot rolling}

A method to estimate the volume fraction of static recrystallization during hot rolling without carrying out metallographic studies of quenched samples was designed. This method could be useful in cases where experimental measurement of $X_{\mathrm{a}}$ by observation of quenched samples is difficult. The first step of this method consists of the application of back extrapolation technique on pairs of stress-strain curves corresponding to 
consecutive hot rolling passes (Fig. 2a). An “apparent” value of recrystallized fraction $\left(X_{\mathrm{a}}\right)$ is obtained. This value is affected by the temperature drop between passes, i.e. it reflects the hardening of the steel derived from cooling that can be seen in phase I of Fig. 2b. The value of $X_{\mathrm{a}}$ is always lower than 1 and it is practically constant and close to $0.9(90 \%)$ at $\mathrm{T}>T_{\mathrm{nr}}$. In line with the classical definition of $T_{\mathrm{nr}}$ and also according to the results of the microstructural studies carried out on quenched samples (Fig. $\mathbf{4}$ and aspect ratio of Fig. 5), the static recrystallization of austenite can be assumed to be complete at temperatures above $T_{\mathrm{nr}}$. To subtract the effect of temperature on austenite strength this hypothesis was adopted. Therefore, the value of $X_{\mathrm{a}}$ in each pass was “normalized”, i.e. it was divided by the average of the values of $X_{\mathrm{a}}$ at temperatures above $T_{\mathrm{nr}}\left(\bar{X}_{\mathrm{a}}\right)$. In this way, the value of the new $X_{\mathrm{a}}\left(X_{\mathrm{a}}{ }^{\prime}\right)$ will be approximately equal to 1 between the first pass and $\mathrm{T}=T_{\mathrm{nr}}$. Finally, it should be taken into account that the values of $X_{\mathrm{a}}$ and $X_{\mathrm{a}}$ ' inform about the austenite recrystallization during a single interpass (i.e. between the ith and $(i+1)$ th passes) but they do not reflect the progressive accumulation of strengthening in an average mixed microstructure compared to the fully recrystallized material existing at temperatures above $T_{\mathrm{nr}}$. For example, if the calculated recrystallized fraction after three consecutive passes is respectively equal to $100,90 \%$ and $80 \%$, the “accumulated” recrystallized fraction after the third interpass time $\left(X_{\mathrm{a}}{ }^{*}\right)$ would not be $80 \%$ but it should be the result of multiplying the successive recrystallized fractions: $100 \% \cdot 90 \% \cdot 80 \%=72 \%$. Summarizing, the mathematical expressions would be:

$X_{a}^{i}=$ Result of Back Extrapolation method applied on curves of passes (i-1) and $i$;

$\overline{X_{a}}=\frac{\sum_{i=2}^{n} X_{a}^{i}}{n-1} ; \quad n=$ number of pass where $\left(T \approx T_{n r}\right)$; 


$$
\begin{aligned}
& \left(X_{a}^{i}\right)^{\prime}=\frac{X_{a}^{i}}{X_{a}} ; \\
& X_{a}^{i} *=\left(X_{a}^{i}\right)^{\prime} X_{a}^{i-1} *
\end{aligned}
$$

It should be taken into account that the value of $\overline{X_{a}}$ should be really the number that makes the average of $X_{\mathrm{a}}{ }^{*}$ between the first pass and $T_{\mathrm{nr}}$ (and not the average of $X_{\mathrm{a}}$ ') to be close to 1 . Then, equation (4) should be replaced by the condition:

$$
\overline{X_{a}} \Rightarrow \frac{\sum_{i=2}^{n} X_{a}^{i} *}{n-1}=\frac{\sum_{i=2}^{n} \frac{X_{a}^{i}}{X_{a}} X_{a}^{i-1} *}{n-1}=1 ; \quad n=\text { number of pass where }\left(T \approx T_{n r}\right)
$$

The values of $X_{\mathrm{a}}$ * depend on $\overline{X_{a}}$, so a numeric resolution process is necessary to make this minor correction in order to calculate $\overline{X_{a}}, X_{\mathrm{a}}$ ' and $X_{\mathrm{a}}{ }^{*}$ more accurately. Figure 6 shows the application of this method to calculate $X_{\mathrm{a}}{ }^{*}$ using the $\sigma-\varepsilon$ plots of Fig. 2a. In agreement with the initial hypotheses, recrystallized fraction $X_{\mathrm{a}}{ }^{*}$ is almost constant and close to 1 until $T_{\mathrm{nr}}$ is attained. Below this temperature, $X_{\mathrm{a}}{ }^{*}$ starts to decrease and austenite accumulates a strengthening. The calculated values of $X_{\mathrm{a}}$ * have been compared to those measured by quantitative metallography $\left(X_{\mathrm{am}}\right)$ on microstructures of quenched samples like those shown in Fig. 4. Figure 7 shows an optical micrograph of same sample as Fig. $\mathbf{4 g}$ taken at higher magnification. Deformed (unrecrystallized) grains are characterized by larger size, elongated shape and usually serrated boundaries. On the other hand, recrystallized grains are finer and more equiaxed [19,31]. The amounts of both kinds of grains were measured by point counting in several fields and the standard area fraction was calculated to quantify the recrystallized volume fraction 
$\left(X_{\mathrm{am}}\right)$. Calculated and observed recrystallized fractions are similar so it can be concluded that the method proposed is adequate and reflects with reasonable accuracy the evolution of recrystallization during hot rolling.

From the stress-strain curves obtained in multipass torsion tests (Fig. 2a) it was also possible to determine the values of the "fractional softening" that takes place between passes. The anisothermal fractional softening (FS) was calculated by means of the following expression $[8,17,35,38,39]$ :

$$
F S(\%)=\frac{\sigma_{m}^{i}-\sigma_{y}^{i+1} \frac{\sigma_{0}^{i}}{\sigma_{0}^{i+1}}}{\sigma_{m}^{i}-\sigma_{0}^{i}} \times 100
$$

where $\sigma_{m}^{i}$ and $\sigma_{y}^{i+1}$ are the maximum and the yield stresses for both, the $i$ th (at temperature $T_{\mathrm{i}}$ ) and (i+1)th (at temperature $T_{\mathrm{i}+1}$ ) passes, respectively. $\sigma_{0}^{i}$ and $\sigma_{0}^{i+1}$ are the yield stresses of a fully recrystallized material for the $i$ th and $(i+1)$ th passes. The yield stresses were determined by the $2 \%$ offset method. $\sigma_{m}^{i}$ and $\sigma_{y}^{i+1}$ are based on the pass-to-pass flow curves of Fig. 2a. $\sigma_{0}^{i}$ and $\sigma_{0}^{i+1}$ are determined from the linear relationship derived from the values of yield stresses $\left(\sigma_{y}\right)$ measured in the stress-strain curves of Fig. 2a corresponding to the temperature range of complete recrystallization $\left(\mathrm{T}>T_{\mathrm{nr}}\right)$

The values of FS are also represented against temperature in Fig. 6. It can be seen that the value of anisothermal fractional softening at temperatures above or close to $T_{\mathrm{nr}}$ properly eliminates the influence of temperature on stress, so the values of $F S$ are close 
to the calculated recrystallized fraction $X_{\mathrm{a}}{ }^{*}$ and the value of $X_{\mathrm{am}}$ measured by optical microscopy (i.e. near 100\%). However, at lower temperatures, mixed (i.e. partially recrystallized) microstructures appear. As mentioned above, the "back extrapolation” method suppresses the recovered fraction from the total softened fraction, so it yields lower values than the double-deformation method used to calculate FS. The fraction of recovery can be remarkably high for short interpass times or low temperatures, i.e. when the degree of recrystallization is lower [19,31]. Besides, the "anisothermal fractional softening” method does not seem to consider accurately the accumulation of successive partial recrystallizations at temperatures lower than $T_{\mathrm{nr}}$ that is expressed in equation (6). As a result, the values of FS start to deviate from $X_{\mathrm{a}}{ }^{*}$ at lower temperatures and at the end of hot rolling, near $A_{\mathrm{r} 3}$, the values of $F S$ are more than $20 \%$ higher than calculated $X_{\mathrm{a}}$ * and $X_{\mathrm{am}}$ measured by metallography.

It is also interesting to note that the percentage of recrystallization when $T_{\mathrm{nr}}$ is reached is not exactly $100 \%$, but about $90 \%$. It is obvious that the accuracy in the determination of $T_{\mathrm{nr}}$ is limited by the temperature step of $25^{\circ} \mathrm{C}$ in multipass hot torsion tests. Besides, the method to determine $T_{\mathrm{nr}}$ through the increase in MFS will always need an appreciable degree of hardening that can easily correspond to 5-10\% of unrecrystallized fraction. Furthermore, the presence of particles at temperatures below the precipitation start will affect to some extent the values of yield, maximum and mean flow stress and consequently the results of these techniques. On the other hand, several authors have previously shown that $T_{\mathrm{nr}}$ does not necessarily correspond to the exact transition from complete to partial recrystallization and, depending on interpass time and pass strain, there can be a certain amount of unrecrystallized austenite after the pass immediately before $T_{\mathrm{nr}}[8,10,35,39]$. Some authors define the lowest temperature above which 
recrystallization between passes is complete (i.e. higher than $85-95 \%$ ) as the “recrystallization limit temperature” (RLT) [40]. The "recrystallization stop temperature” (RST) would be the highest temperature at which recrystallization is completely absent (i.e. less than 5\%) [40]. Radovic et al. [39] approximated the FS versus $(1 / T)$ plots by three linear segments, which intersect at two temperatures that can be assimilated to RLT and RST. These authors found that $T_{\mathrm{nr}}$ correlates well with RLT, but Abad et al [35] affirm that $T_{\mathrm{nr}}$ values are located between RLT and RST. Figure 8 shows that RLT is slightly higher than $T_{\mathrm{nr}}$. The second change in slope that determines RST is not easy to locate, probably because $X_{\mathrm{a}} *$ is higher than $10 \%$ even at low temperatures close to $A_{\mathrm{r} 3}$. For example, Fig. 7 shows that very small, equiaxed recrystallized grains can be found in the sample deformed at $775^{\circ} \mathrm{C}$ and quenched from $750{ }^{\circ} \mathrm{C}$. This means that although the austenite has suffered several deformations in the “no-recrystallization” temperature range, a certain fraction of recrystallization during interpass time is still possible at those low temperatures.

On the other hand, the comparison of Fig. 3 to Figs. 4-8 lets to conclude that the increasing value of $\Delta \sigma$ as long as samples are cooled is an accurate qualitative indication of the progressive strengthening of austenite below $T_{\mathrm{nr}}$ [34].

\subsection{Effect of successive hot rolling passes. Comparison between SRCT and $T_{n r}$}

A comparative study of the values of $T_{\mathrm{nr}}$ and SRCT was attempted with the assistance of plots and pictures of Figs. 1a, 2b, 4 and 5. Comparison of these parameters is not easy, as both represent the start of inhibition of recrystallization but they do not have the 
same definition [10]. SRCT is determined by isothermal tests and is independent of the time, whereas $T_{\mathrm{nr}}$ is determined by means of continuous cooling rolling simulations and depends on $\Delta \mathrm{t}$. $T_{\mathrm{nr}}$ presents a value lower than SRCT in the steel studied. According to theory, the value of $T_{\mathrm{nr}}$ in microalloyed steels would be higher than SRCT for shorter interpass times and would pass through a minimum, which occurs at $\Delta \mathrm{t}=10-15 \mathrm{~s}$. This interval reflects the solute drag effect of alloying elements [41]. For medium times, $T_{\mathrm{nr}}$ raises with increasing interpass times because of the higher volume fraction of fine precipitates that exert a strong pinning effect. Finally, for interpass times longer than 50 $\mathrm{s}, T_{\mathrm{nr}}$ decreases again as a consequence of particle coarsening [39,41].

Fig. 1a indicates that the value of static recrystallization at $950{ }^{\circ} \mathrm{C}$ when isothermal time after deformation is $20 \mathrm{~s}$ is approximately equal to $40 \%$. At that point, the curve of $X_{a}$ is in the end of first the plateau of inhibition of recrystallization by precipitation. However, Fig. $\mathbf{2 b}$ shows that austenite presents complete recrystallization at $950^{\circ} \mathrm{C}$ ( $\mathrm{T}>T_{\mathrm{nr}}$ ) with an interpass time of $20 \mathrm{~s}$. As seen in Fig. 5, the application of successive rolling passes (especially at temperatures above $T_{\mathrm{nr}}$ ) provokes an austenite grain refinement. As equation (2) shows, this refinement accelerates recrystallization kinetics. When grain is refined, the area of austenite grain boundaries (potential nucleation sites) increases. Besides, a reduction in grain size can contribute together with strain applied to augment the stored energy due to deformation [42]. The curves of recrystallized fraction against time are then shifted to shorter times. Thus, a steel that is being deformed at temperatures below SRCT can pass the stage of inhibition of recrystallization by induced precipitation delimited by the plateaus in Fig. 1a and reach complete recrystallization in a much shorter time than the indicated in $X_{\mathrm{a}}(\mathrm{t})$ curves. In this case, the strain induced precipitation could be expected to happen after rolling 
passes applied at temperatures above $T_{\mathrm{nr}}$, as grain refinement also accelerates precipitation [43].

Acceleration of recrystallization (displacement of $X_{\mathrm{a}}(\mathrm{t})$ curves towards shorter times and drop in SRCT value) derived from grain refinement is verified observing the microstructures shown in Figures $\mathbf{4 b}$ and 9. Both specimens have been quenched from $950{ }^{\circ} \mathrm{C}$ after waiting $20 \mathrm{~s}$ following a deformation of $\varepsilon=0.20$. However, the first one corresponds to a simulation of 8 passes with a last deformation at $975{ }^{\circ} \mathrm{C}$ and the second is taken from a double deformation isothermal test. In other words, Fig. $\mathbf{4 b}$ corresponds to the ninth point in the MFS curve of Fig. $2 \mathbf{b}\left(\mathrm{T}>T_{\mathrm{nr}}\right)$ and the eight point in Fig. $6\left(X_{a}{ }^{*}\right.$ $\approx 100 \%)$ whereas Fig. 9 coincides with the end of the first plateau in Fig. 1a $\left(X_{\mathrm{a}}=\right.$ 40\%). As a result, the sample from the rolling simulation test presents fine and rather equiaxed grains, while the sample taken from double deformation test shows a mixed microstructure with many coarser, elongated grains. The accuracy of the back extrapolation method in determining the recrystallized fraction in isothermal tests can be observed comparing the calculated value of $X_{\mathrm{a}}$ with the measured value by optical microscopy (about 35\%).

To make a more appropriate comparison between $T_{\mathrm{nr}}$ and SRCT, experimental value of SRCT obtained in isothermal double-deformation tests should be replaced by a calculated value where the influence of actual austenite grain size before deformation in the multipass tests is considered. According to the model of Medina et al. for SRCT, this temperature depends on several variables affecting microstructural evolution during hot deformation (strain $\varepsilon$, strain rate $\dot{\varepsilon}$, initial grain size $D$ and chemical composition) [9]: 
$\operatorname{SRCT}(\mathrm{K})=T_{\mathrm{s}}-708.2[X \cdot 1000]^{0.38} \varepsilon^{0.3} \dot{\mathcal{\varepsilon}}^{0.16} D^{-0.34}$

where $T_{\mathrm{s}}$ is the solubility temperature of $\mathrm{VN}$ and $X$ represents $(\% \mathrm{~V})(\% \mathrm{~N})$ for $\mathrm{V}$ microalloyed steels. It can be seen that SRCT is equal to $T_{\mathrm{s}}$ when strain or strain rate are zero.

In Fig 5, it can be seen that austenite grain size is equal to $19 \mu \mathrm{m}$ when temperature is close to $T_{\mathrm{nr}}\left(897^{\circ} \mathrm{C}\right)$. If this value is introduced in equation (9), then the calculated SRCT would be equal to $857^{\circ} \mathrm{C}$, i.e. much closer and even lower than $T_{\mathrm{nr}}$. Figure 10 shows the result of making this calculation in several hot rolling simulation passes. It can be seen that, as long as austenite grain is refined, SRCT value would converge to $T_{\mathrm{nr}}$. There is however a certain error that can be partially attributed to the discrepancy between the model of Eq. (9) and the experimental value of SRCT $\left(1076^{\circ} \mathrm{C}\right)$. It can be expected that the residual amount of $\mathrm{Ti}(0.003 \%)$ would cause $\mathrm{TiN}$ particles to precipitate at high temperatures. These particles would serve as nucleation sites for new strain-induced vanadium precipitates [22] and experimental SRCT would be slightly higher than the value obtained with the model.

\section{Conclusions}

- By means of thermomechanical tests and metallographic studies carried out in a Vmicroalloyed steel, it has been verified that, for the deformation conditions used, norecrystallization temperature $\left(T_{\mathrm{nr}}\right)$ approximately corresponds to the temperature where 
recrystallization starts to be incomplete, as observable by the increase of MFS in a multipass torsion test.

- However, incomplete recrystallization is visually evident at temperatures $50{ }^{\circ} \mathrm{C}$ below $T_{\mathrm{nr}}$, where grain elongation and increase in aspect ratio with temperature drop start to be significant.

- The fraction of austenite static recrystallization during hot rolling $\left(X_{\mathrm{a}}^{*}\right)$ can be estimated by means of a calculation method that only needs the stress-strain data of thermomechanical tests. Comparison with metallographic studies verifies the accuracy of this method.

- The value of anisothermal fractional softening (FS) is close to the recrystallized fraction at temperatures above or close to $T_{\mathrm{nr}}$. However, at lower temperatures, this parameter overestimates the value of austenite recrystallization during hot rolling because it includes the percentage of recovery and does not properly consider the accumulation of strengthening between successive passes. Consequently, the value of FS at temperatures near $A_{\mathrm{r} 3}$ could be more than 20\% higher than $X_{\mathrm{a}}{ }^{*}$.

- The value of $T_{\mathrm{nr}}$ obtained in mean flow stress (MFS) vs. (1/T) plots is close to the value of recrystallization limit temperature (RLT) measured in FS-(1/T) plots.

- Accumulated stress measured in the MFS plots represents a suitable indication of the progressive strengthening of austenite below $T_{\mathrm{nr}}$.

- A large proportion of austenite grain refinement is achieved in the first hot deformation passes after reheating, i.e. at temperatures much higher than $T_{\mathrm{nr}}$. For example, the value of grain size measured after interpass time is divided by six in the first six passes.

- The effect of grain size on recrystallization and precipitation kinetics and their mutual interaction helps to explain the discrepancy in the microstructure observed at the same 
quenching temperature on isothermal double-deformation tests and continuous-cooling multipass hot rolling simulations. Besides, if this effect is considered, SRCT temperature determined in isothermal double deformation tests approaches to $T_{\mathrm{nr}}$ obtained in multipass continuous cooling tests.

\section{References}

[1] C.M. Sellars, in: C.M. Sellars, C.J. Davies (Eds.), Proc. Int. Conf. On Hot Working and Forming Processes, The Metal Society of London, 1980, pp. 3-15.

[2] F.H. Samuel, S. Yue, J.J. Jonas, B.A. Zbinden, ISIJ Int. 29 (1989) 878-886.

[3] S. F. Medina, A. Quispe, P. Valles, J. L. Baños, ISIJ Int. 39 (1999) 913-922.

[4] J. H. Beynon, C. M. Sellars, ISIJ Int. 32 (1992) 359-367.

[5] P. D Hodgson, R. K. Gibbs, ISIJ Int. 32 (1992) 1329-1338.

[6] P. Choquet, A. Le Bon, C. Perdrix, in: H.J. McQueen, J.P. Bailon, J.I. Dickson, J.J. Jonas and M.G. Akben, (Eds.), Proc. of 7th Int. Conf. on Strength of Metals and Alloys vol. 2, Pergamon Press, Oxford, 1985, pp. 1025-1030.

[7] S. F. Medina, A. Quispe, M. Gomez, Mater. Sci. Tech-Lond. 19 (2003) 99-108.

[8] M. Arribas, B. Lopez, J.M. Rodriguez-Ibabe, Mater. Sci. Eng. A 485 (2008) 383394.

[9] S. F. Medina, A. Quispe, M. Gomez, Mater. Sci. Tech-Lond. 17 (2001) 536-544.

[10] S. F. Medina, Mater. Sci. Tech-Lond. 14 (1998) 217-221.

[11] B. Engl, K. Kaup, in: A. J. DeArdo, G. A. Ratz, P. J. Wray, (Eds.) Proceedings of the International Conference on Thermomechanical Processing of Microalloyed Austenite, TMS AIME, Pittsburgh, PA, 1982, pp. 467-482. 
[12] M. Umemoto, A. Hiramatsu, A. Moriya, T. Watanabe, S. Nanba, N. Nakajima, G. Anan, Y. Higo, ISIJ Int. 32 (1992) 306-315

[13] J.S. Perttula, L.P. Karjalainen, Mater. Sci. Tech-Lond. 14 (1998) 626-630.

[14] A.I. Fernandez, B. Lopez, and J.M. Rodriguez-Ibabe, Scripta Mater. 40(1999) 543-549.

[15] J.J. Jonas, E.I. Poliak, Mater. Sci. Forum 500-501 (2005) 15-25.

[16] S. Serajzadeh, Mater. Sci. Eng. A 448 (2007) 146-153.

[17] W.J. Liu, M.G. Akben, Can. Metall. Q. 26 (1987) 145-153.

[18] A. Streisselberger, R. Kaspar, O. Pawelski, Metall. Trans. 16A (1985) 67-72.

[19] E.J. Giordani, A.M. Jorge, Jr., O. Balancin, Scripta Mater 55 (2006) 743-746.

[20] N.D. Ryan, H.J. McQueen, J. Mater. Process. Tech. 36 (1993) 103-123.

[21] L. P. Karjalainen, T. M. Maccagno, J. J. Jonas, ISIJ Int. 35 (1995) 1523-1531.

[22] M. Gomez, S.F. Medina, J. I. Chaves, Mater. Sci. Forum 550 (2007) 417-422.

[23] A. Ardehali Barani, F. Li, P. Romano, D. Ponge, D. Raabe, Mater. Sci. Eng. A 463 (2007) 138-146.

[24] A. M. Elwazri, E. Essadiqi, S. Yue, ISIJ Int. 44 (2004) 744-752.

[25] E. T. Turkdogan, Iron Steelmaker 16 (1989) 61-75.

[26] M.I. Vega, S.F. Medina, A. Quispe, M. Gomez, P.P. Gomez, Mater. Sci. Eng. A 423 (2006) 253-261.

[27] H. L. Andrade, M. G. Akben, J. J. Jonas, Metall. Trans. 14A (1983) 1967-1977

[28] S Hansen, J. B. Van der Sande, M. Cohen, Metall. Trans. 11A (1980) 387-402.

[29] K. J. Lee, Scripta Mater. 40 (1999) 837-843

[30] H. S. Zurob, Y. Brechet, G. Purdy, Acta Mater. 49 (2001) 4183-4190.

[31] C. Devadas, I. V. Samarasekera, E. B. Hawbolt, Metall. Trans. 22A (1991) 335349. 
[32] A. Faessel, Rev. Métall. Cah. Inf. Tech. 33 (1976) 875-892.

[33] M. Gomez, S.F. Medina, P. Valles, A. Quispe, Mater. Sci. Forum 480-481 (2005) 489-493.

[34] M. Gomez, O. Hernanz, S. F. Medina, P. Tarin, Steel Res. 73 (2002) 446-452.

[35] R. Abad, A. I. Fernández, B. Lopez, J. M. Rodriguez-Ibabe, ISIJ Int. 41 (2001) 1373-1382.

[36] E. J. Palmiere, C. I. Garcia, A. J. Deardo, Metall. Mater. Trans. 27A (1996) 951960.

[37] M. Gomez, S. F. Medina, P. Valles, ISIJ Int. 45 (2005) 1711-1720.

[38] A. Bapari, A. Najafizadeh, M. Moazeny, A. Shafyei, Mater. Sci. Eng. A 491 (2008) 258-265.

[39] N. Radovic, D. Drobnjak, ISIJ Int. 39 (1999) 575-582.

[40] B. Dutta, C. M. Sellars, Mater. Sci. Tech-Lond. 3 (1987) 197-207.

[41] D. Q. Bai, S. Yue, W. P. Sun, J. J. Jonas, Metall. Trans 24A (1993) 2151-2159.

[42] M. Kazeminezhad, Mater. Sci. Eng. A 486 (2008) 202-207.

[43] A. Quispe, S. F. Medina, M. Gomez, J. I. Chaves, Mater. Sci. Eng A 447 (2007) $11-18$. 
Table 1. Chemical composition of the steel studied (weight \%).

\begin{tabular}{ccccccccccc}
\hline $\mathrm{C}$ & $\mathrm{Si}$ & $\mathrm{Mn}$ & $\mathrm{P}$ & $\mathrm{S}$ & $\mathrm{Al}$ & $\mathrm{Cr}$ & $\mathrm{V}$ & $\mathrm{Ti}$ & $\mathrm{N}$ & $\mathrm{O}$ \\
\hline 0.48 & 0.28 & 1.45 & 0.024 & 0.018 & 0.009 & 0.22 & 0.13 & 0.003 & 0.0200 & 0.0044 \\
\hline
\end{tabular}


Table 2. Calculated solubility temperatures of the steel studied [25]. Reheating temperature (reheating time $=10 \mathrm{~min}$ ) and measured austenite grain size $\left(D_{\gamma}\right)$ at reheating temperature.

\begin{tabular}{ccccccc}
\hline \multicolumn{3}{c}{ Solubility temperatures $\left({ }^{\circ} \mathrm{C}\right)$} & & & Reheating & \\
& & & & & \\
& & & \\
VN & $\mathrm{VC}_{0.75}$ & $\mathrm{TiN}$ & $\mathrm{TiC}$ & & temperature $\left({ }^{\circ} \mathrm{C}\right)$ & \\
\hline 1141 & 904 & 1368 & 979 & & 1200 & 155 \\
\hline
\end{tabular}




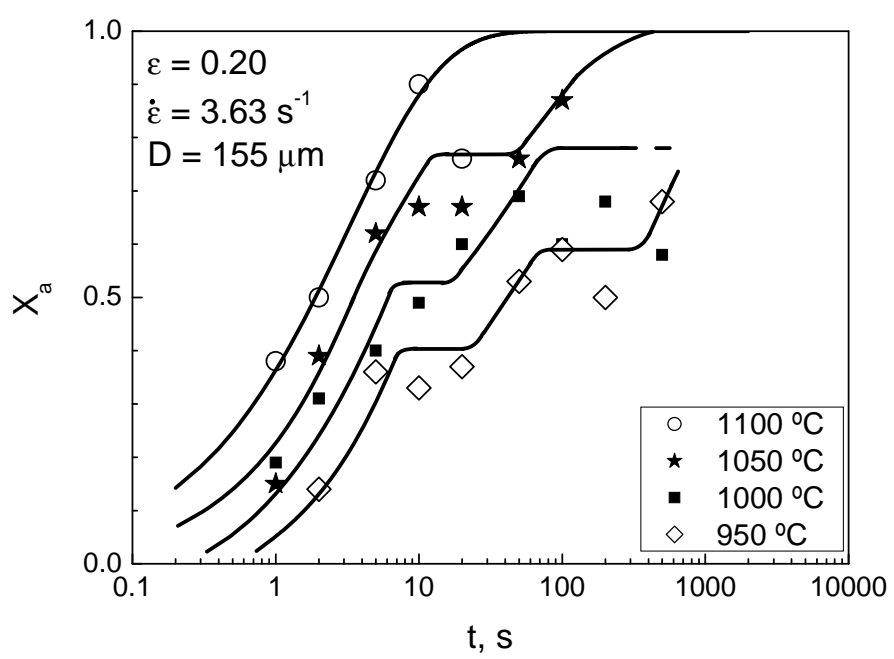

a)

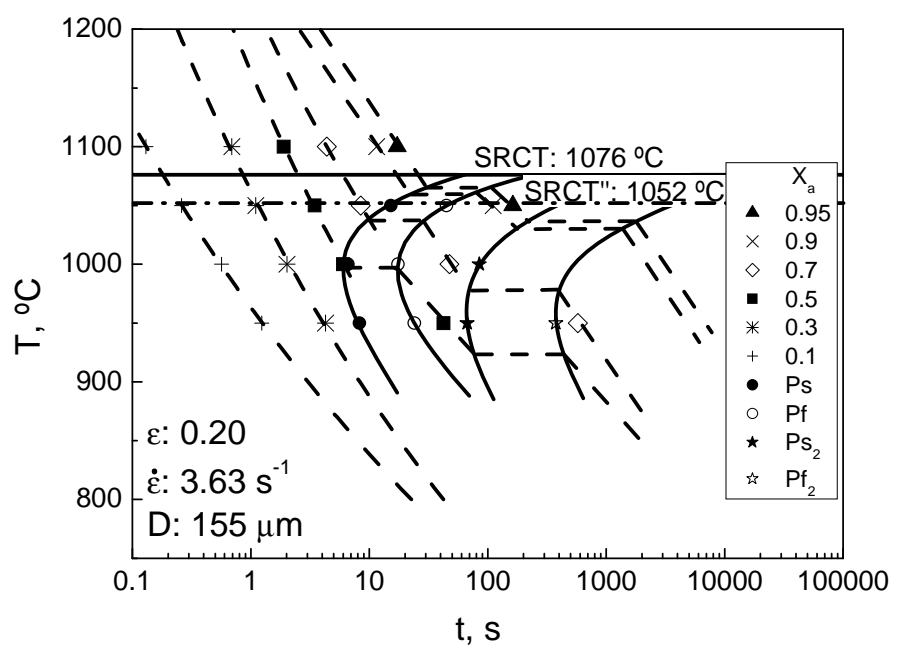

b)

Fig. 1. Double deformation isothermal test. a) Volume fraction of static recrystallization $\left(X_{\mathrm{a}}\right)$ versus holding time after deformation; b) RPTT diagram. 


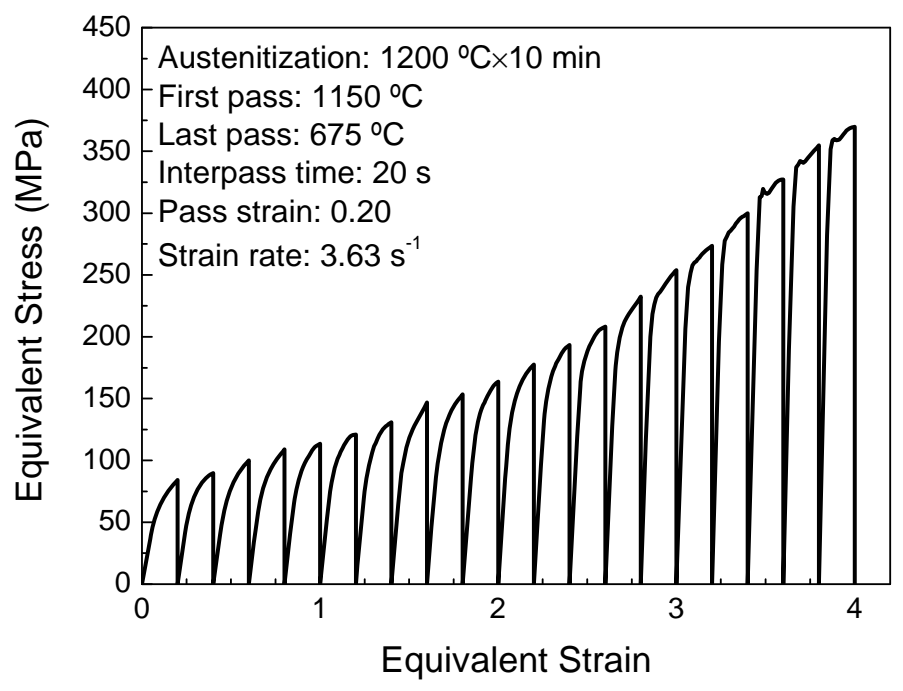

a)

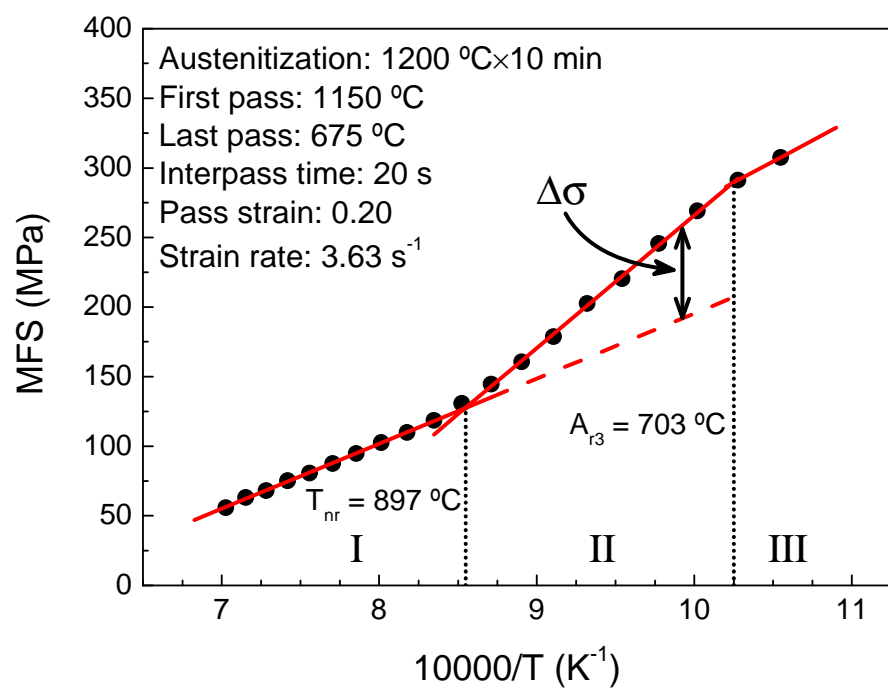

b)

Fig. 2. Multipass hot rolling simulation. a) Stress-strain curves corresponding to a 20pass hot torsion deformation schedule; b) Mean flow stress versus the inverse of absolute temperature. 


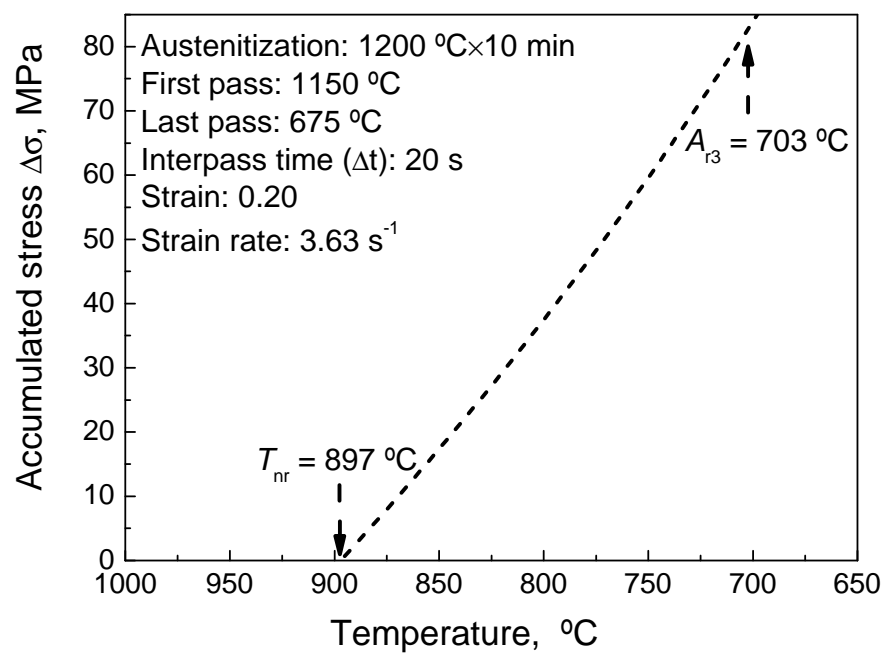

Fig. 3. Evolution of austenite accumulated stress $(\Delta \sigma)$ during hot rolling. 


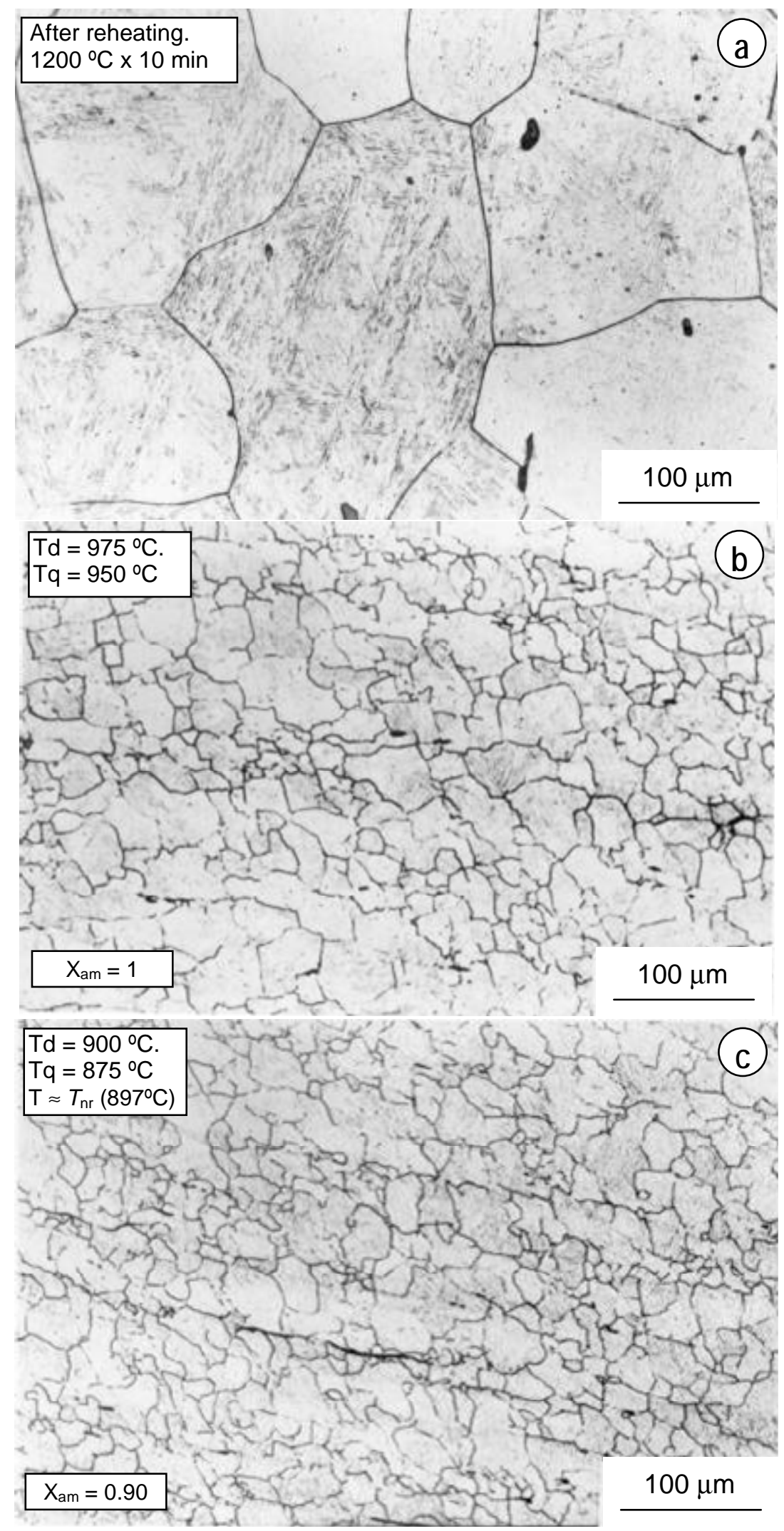




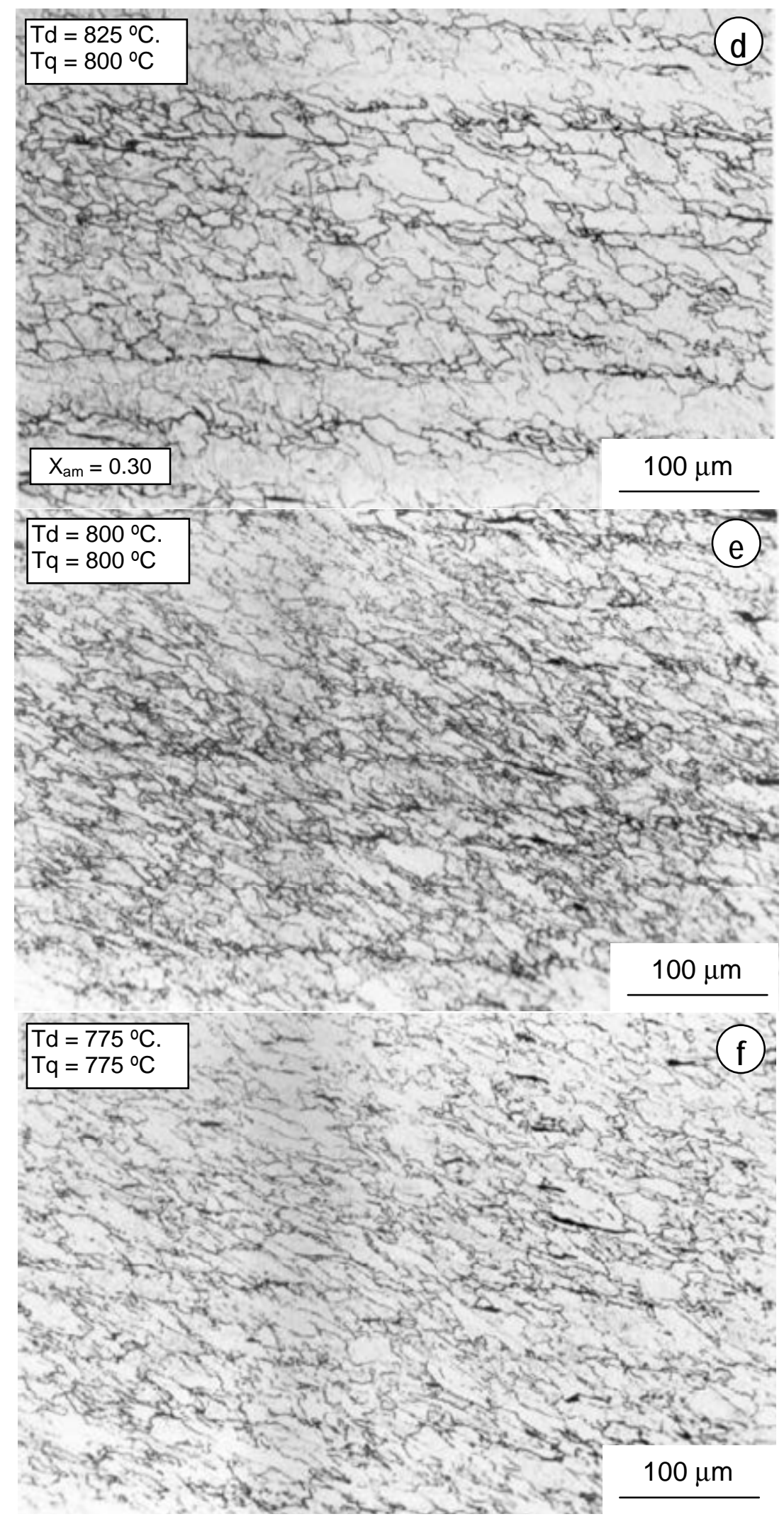




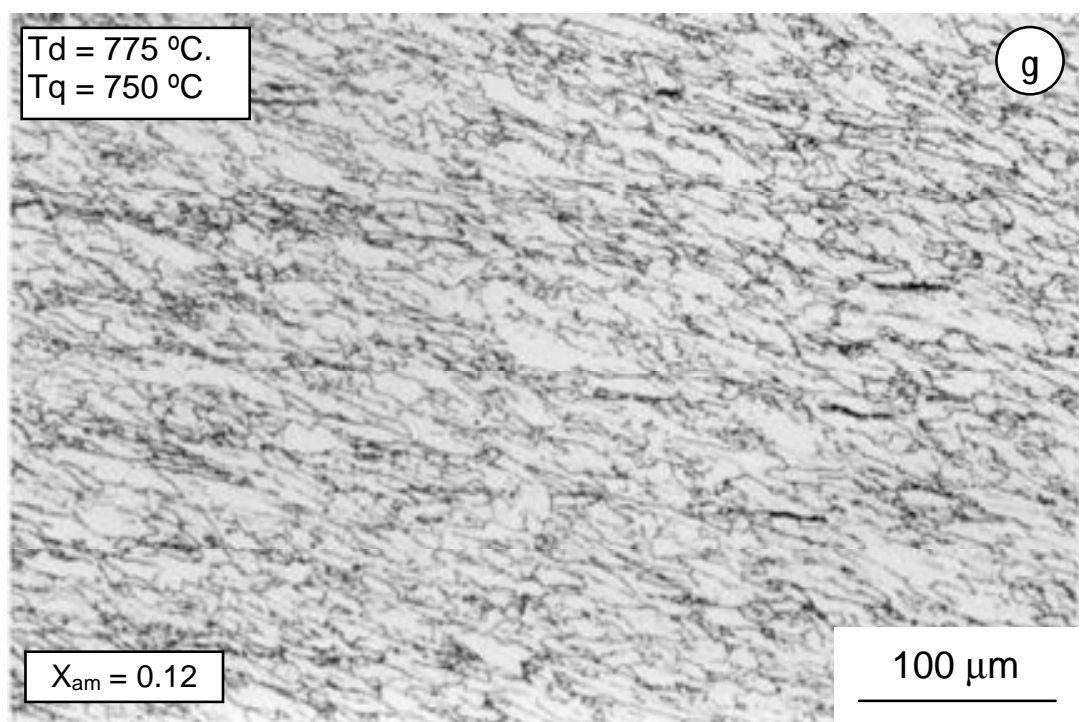

Fig. 4. Microstructures obtained at different stages of hot rolling simulation. $\varepsilon=0.20 ; \dot{\varepsilon}$ $=3.63 \mathrm{~s}^{-1} ; \Delta \mathrm{t}=20 \mathrm{~s}$; “Td” means deformation temperature and "Tq" quenching temperature. $X_{\mathrm{am}}$ is the recrystallized fraction measured by metallography after observation of several fields. 


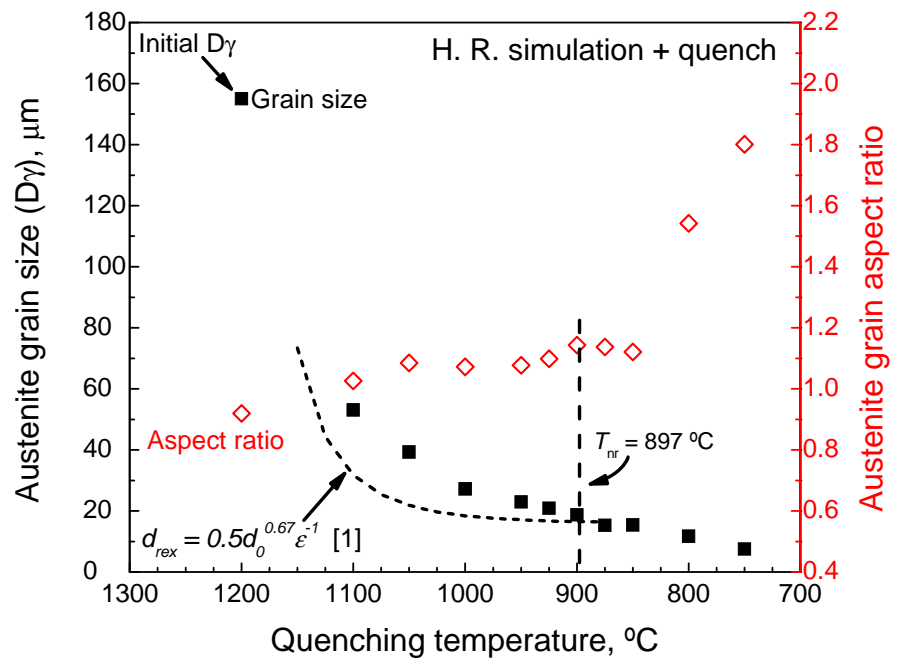

Fig. 5. Evolution of austenite microstructure as a function of deformation temperature during hot rolling simulation. Average austenite grain size and average austenite grain aspect ratio. 


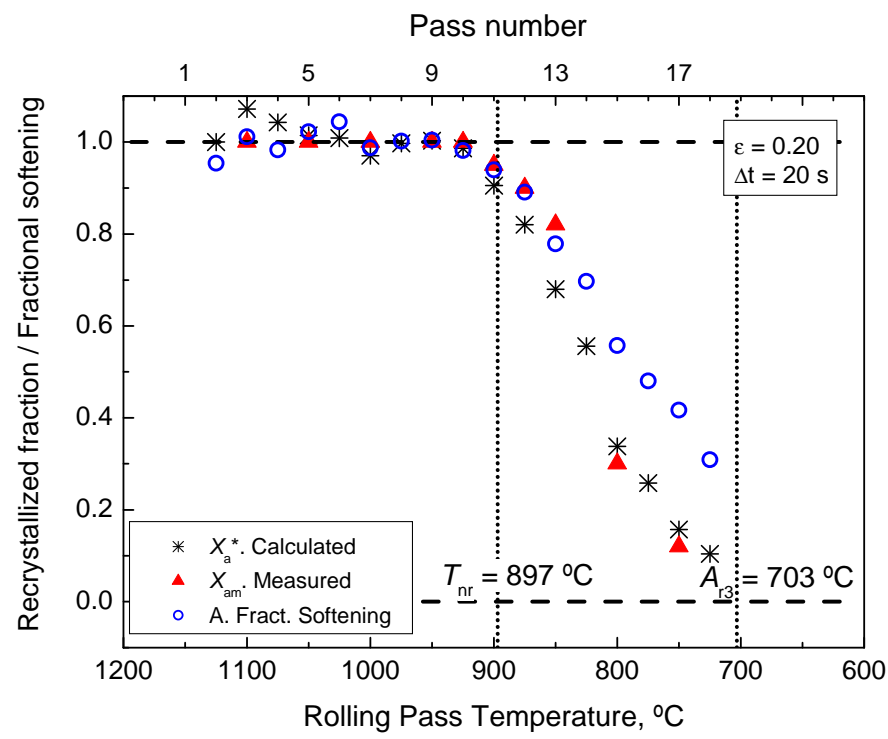

Fig. 6. Estimation of statically recrystallized fraction $\left(X_{\mathrm{a}}{ }^{*}\right)$ during a hot rolling simulation using Eqs. (3)-(7). Comparison with experimental values measured by optical microscopy $\left(X_{\mathrm{am}}\right)$ and anisothermal fractional softening measured with Eq. (8). 


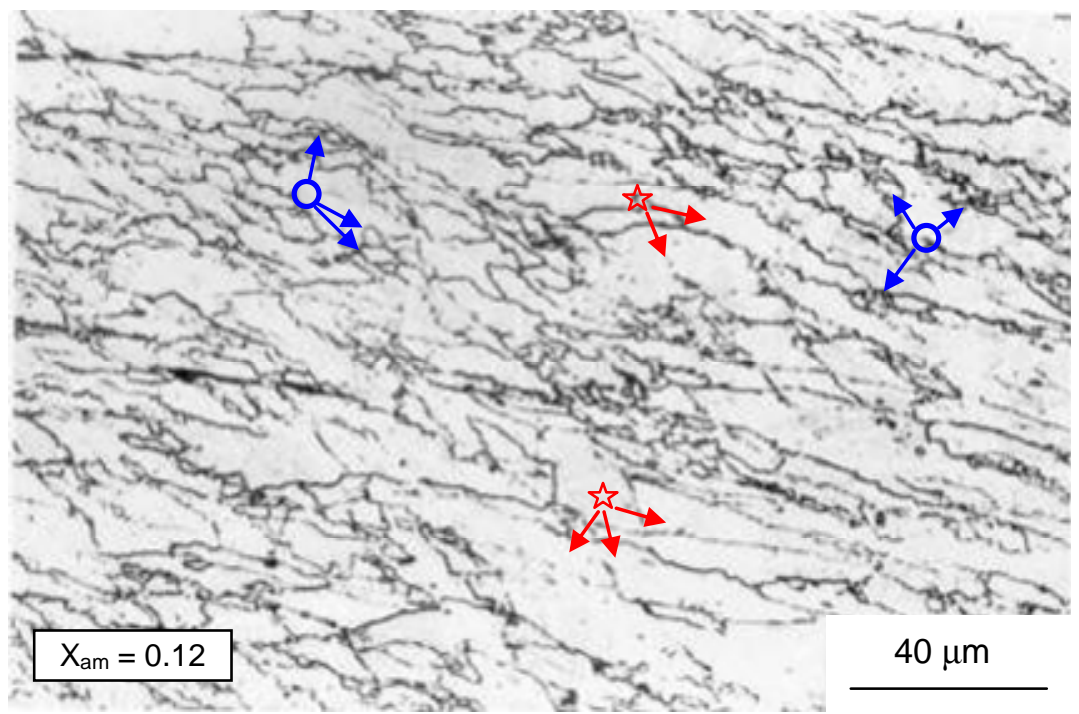

Fig. 7. Microstructure obtained after a hot rolling simulation of 16 passes. $\varepsilon=0.20 ; \dot{\varepsilon}$ $=3.63 \mathrm{~s}^{-1} ; \Delta \mathrm{t}=20 \mathrm{~s}$; last pass temperature $=775^{\circ} \mathrm{C}$; quenching from $750{ }^{\circ} \mathrm{C}$ (same sample as Fig. 4g). Calculated recrystallized fraction $\left(X_{\mathrm{a}}^{*}\right)=0.16$; Measured recrystallized fraction $\left(X_{\mathrm{am}}\right)=0.12$; Fractional softening $(F S)=0.42$. Examples of recrystallized grains are indicated by circles and unrecrystallized grains are denoted by stars. $X_{\mathrm{am}}$ is always obtained after observation of several fields. 


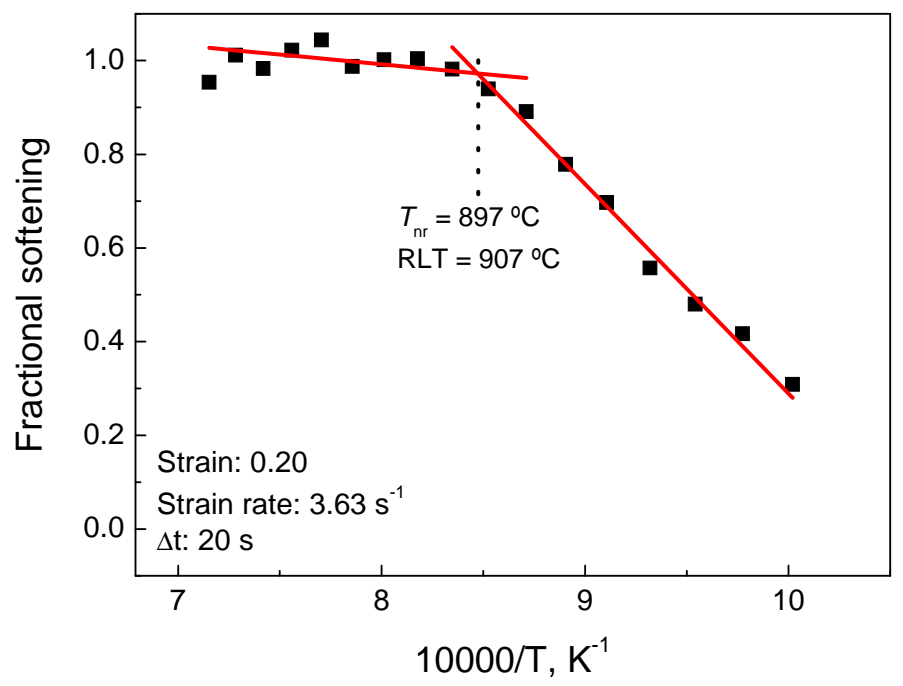

Fig. 8. Anisothermal fractional softening versus the inverse of pass absolute temperature. 


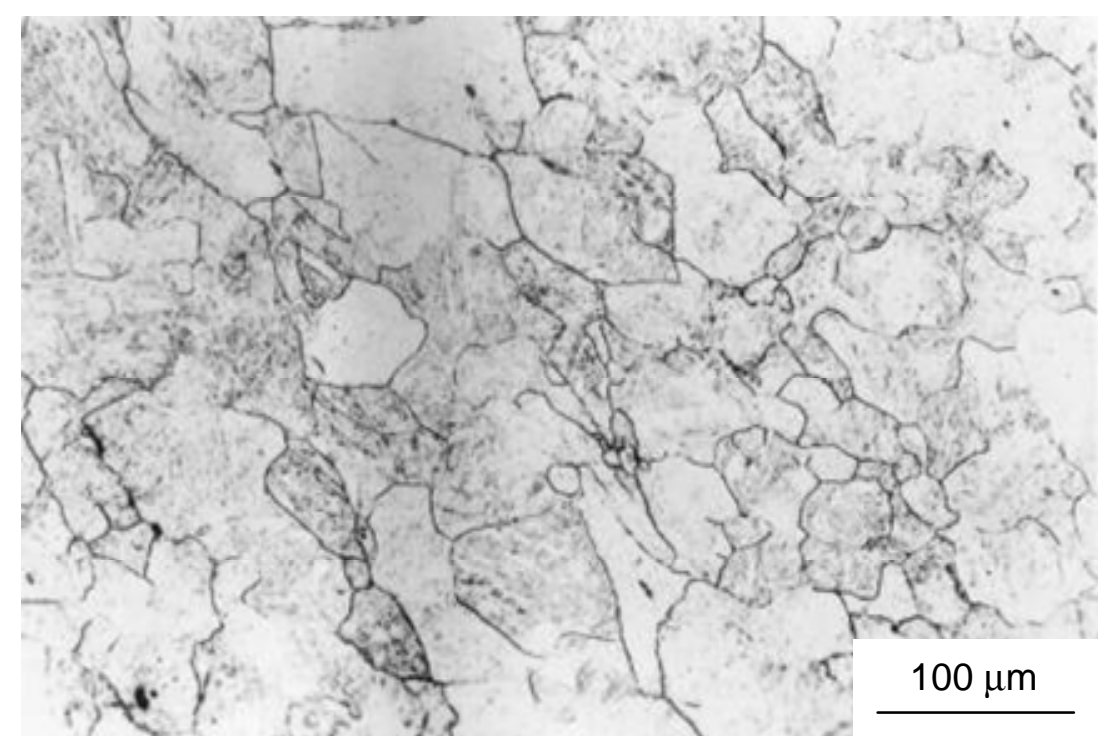

Fig. 9. Microstructure of austenite deformed at $950^{\circ} \mathrm{C} . \varepsilon=0.20 ; \dot{\varepsilon}=3.63 \mathrm{~s}^{-1}$; $\mathrm{Td}=\mathrm{Tq}=$ $950{ }^{\circ} \mathrm{C}$; Isothermal holding time $=20 \mathrm{~s} ; X_{\mathrm{a}}=0.40, X_{\mathrm{am}}=0.35$. 


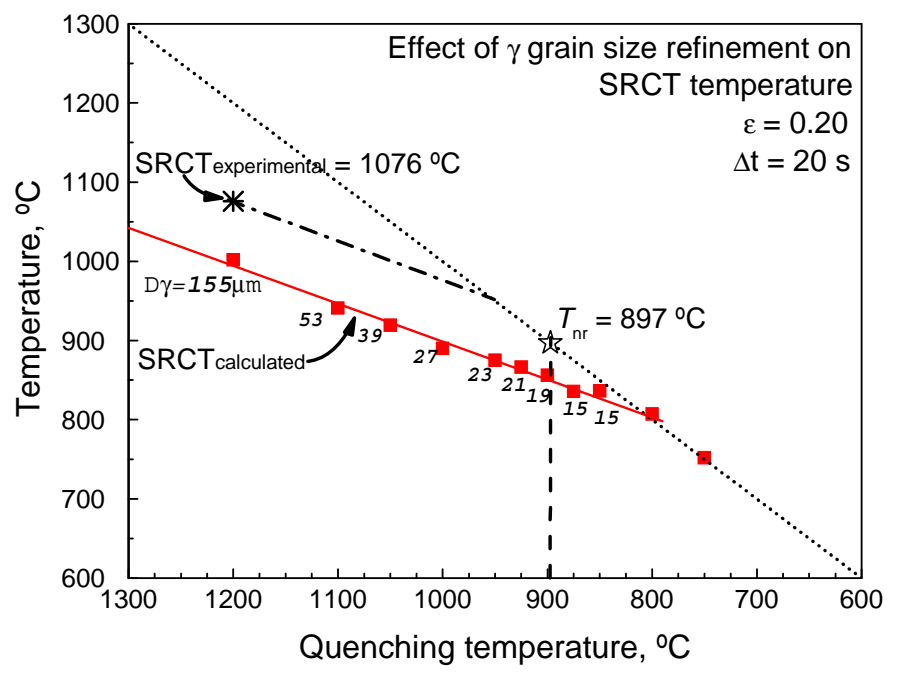

Fig. 10. Effect of austenite grain refinement on the temperature below which static recrystallization is incomplete. The values of grain size shown in Fig. 5 (numbers in italics) are introduced in Equation (9) to estimate SRCT temperature in each rolling pass. 